\title{
"Open": the changing relation between citizens, public administration, and political authority
}

Towards researching the Public Value of Open Government

\author{
Ursula Maier-Rabler, Stefan Huber
}

ICT\&S Center for Advanced Studies and Research in Information and Communication Technologies \& Society, University of Salzburg, Sigmund-Haffner-Gasse 18, A-5020 Salzburg, ursula.maier-rabler@sbg.ac.at, stefan.huber@sbg.ac.at, +43/(0) $662 / 8044-4801$

\begin{abstract}
Open" is not just a fancy synonym for transparent and accountable. The "Open" in Open Government, Open Data, Open Information, and Open Innovation stands for the changing relation between citizens and authorities. Many citizens no longer accept the passive stance representative democracy held for them. They take an active approach in setting up better means of collaboration by ICTs. They demand and gain access to their historically grown collective knowledge stored in government data. Not just on a local level, they actively shape the political agenda. Open Government is to be seen in the context of citizens' rights: the right to actively participate in the process of agenda-setting and decision-making. Research into open government needs to address the value of the changing relation between citizens, public administration, and political authority. The paper argues finally for the application of the Public Value concept to research into open government.
\end{abstract}

Keywords: Open Government, Open Data, Open Information, Open Innovation, Open Commons, Open Collaboration, Open Government Platform, Public Value

Acknowledgement: The authors would like to thank Sonja Einböck for proofreading the paper.

A narrow definition of open is not just an antagonism in the eyes of witty philosophers. The people of opendefinition.org (http://opendefinition.org) set out to provide a clear set of criteria for openness. This is the latest definition of open they offer: "A piece of content or data is open if anyone is free to use, reuse, and redistribute it - subject only, at most, to the requirement to attribute and share-alike." Their contribution is essential in complementing creative commons and the open access movement in the context of open data and open knowledge. But the limitation of openness to synonyms like transparency and accountability in the context of open government still misses the innovative approach that lies at the heart of open. In a broader understanding, "open" stands for a changing relation between citizens and authorities; i.e. a gain of power in the hands of the governed in respect to the governors. Similarly, the secretary-general of the OECD concluded in its 2011 report on innovative and open government, that in the context of the current crisis, technological shift and reliance on IT, "citizens and civil society will be empowered to take on greater responsibility and start new partnerships with the public sector. Therefore, collaboration with citizens and civil society will become a cornerstone for future public sector reforms." (OECD, 2011, p. 13).

Originally, in its most basic sense, open government referred to the right of people to access governmental documents and proceedings (Lathrop, Ruma, 2010). But meanwhile, the meaning of the open government concept has evolved. Influenced by the experiences of the open source software movement, the open government approach has incorporated claims for participation in the procedures of government. The specific pattern of thinking present in the open software community - that people may built on open software developed by others and contribute actively to its further advancement became a significant feature in the open government movement, too. Lathrop and Ruma (2010, p. xix) pinned this down:

"Just as open source software allows users to change and contribute to the source code of their software, open government now means government where citizens not only have access to information, documents, and proceedings, but can also become participants in a meaningful way."

Social networking sites, crowdsourcing initiatives, the creative re-interpretation of open data (just to list a few applications of the web 2.0) are currently enforcing this trend. 
This paper explores the meaning and features of e-participation in the context of open government. First, it addresses the reason why democratic innovation is needed. Second, it discusses the changing relation between citizens, public administration, and political authority in various aspects of open government. We understand that citizens have got a right to own the aggregated data government collects of them and to use open government platforms as a tool for citizen empowerment. The paper finally concludes that the public value of open government needs to be studied applying the public value research approach (cf. Moore, 1995; Benington, Moore 2011).

\section{The need for democratic innovation in times of post-democracy}

Mass media and industrial information economy have been the context in which complex modern societies have evolved. The frameworks of democratic institutions have been shaped by and largely reflect the according way of information production and exchange. Benkler $(2006$, p. 460$)$ has pointed out that institutional frameworks still "enforce these conceptions as practiced reality", even when the conceptual model initially shaping them is slowly vanishing. The cultural practice coming up with mass-media television culture was characterized by the "passive consumption of polished, finished goods" (Benkler, 2006, p. 466). It may not be surprising that political institutions still favor nicely labeled packages ready to present to the media, compared to communication about seemingly unfinished work in progress. The first, being in accordance with known long-lasting cultural patterns, fits well with the institutional logic of representative democracy, while the last is considered an upcoming cultural innovation.

Crouch picked the relation between citizens and democratic institutions as a central theme in his work about post-democracy. He delineated post-democracy to be the last of three phases of democratic development. At the time of his writing (2008), he considered western democracy to have entered the phase of post-democracy. In post-democracy, elections do still take place, and they still have the power to chase governments out of office, but the communication patterns about politics have changed. Competing teams of PR-experts dominate and control the topics of public debate during election campaigns and thereby turn democratic elections into spectacles (Crouch, 2008, p. 10). The majority of citizens remains in a passive, muted and apathetic stance, reacting only to signals they are exposed to. Political decisions are in the meantime made behind closed doors. Post-democracy lacks one of the main characteristics of democracy: widespread public debate and political participation. Claims for more participation are often rooted in perceived democratic deficits that stem from lacking government responsiveness to citizen's claims, or missing governance legitimacy (Warren, 2011, p. 1)

What neither Crouch nor Warren sufficiently broach is the role of the Internet. The beginning replacement of twentieth-century remote media by the Internet is going hand in hand with a change in human behavior. Benkler (2006) stated the shift of time people spend with certain kinds of media and the changing role from passive to active behavior that goes with it.

"Some of the time that used to be devoted to passive reception of standardized finished goods through a television is now reoriented toward communicating and making together with others, in both tightly and loosely knit social relations." (Benkler, 2006, p. 467)

In the upcoming of a more participatory cultural production system Benkler sees a major advantage compared to the professional mass culture of the industrial age. Citizens that engage in communication and making together correspond with Crouch's idea of the true character of ideal democracy $(2008$, p. 140). But instead of raising the question how ICTs can serve in a more participatory democracy, Crouch only very generally asked what could be done to make the democratic quality of communities a topic on the agenda. He explicitly urged to find alternative options to articulate political dissatisfaction and to support political mobilization (p. 151). Almost simultaneously (2007), Coleman came up with similar analyses of the shortcomings of current institutional arrangements. He identified a deliberative deficit in contemporary democracies due to "an absence of spaces or occasions for the public to engage in open and critical discussion in which opinions can be exchanged and reviewed and policy decision influenced" (p. 370). As a means to deal with the shortcomings of democracy, Coleman discusses E-Democracy. It is important to avoid the deterministic trap in this discussion. New media technologies are not bound to serve more democratic practices. 
The development of technologies is socially shaped and can take both a more or less democratic turn. This is particularly true for the participatory character of ICTs. In Coleman's terms "media technologies are neither inherently participatory nor exclusive, but depend upon cultural practices and policy contestations" (p. 363). Many e-government applications are poor in participatory value. Balnaves and Willson identify the experience with e-government as one that has "largely blotted out and even worked against, any concomitant development of enhanced citizen participation" (2011, p. 123). According to them, policy-makers have so far mainly ignored the potential of the Internet to advance civic participation.

What characterizes social software is a "pluralistic ethos of shared and dynamic knowledge" (Coleman, 2007, p. 369). This quality of social software is particularly important in order to distinguish it from other software that emphasizes passive or repetitive behavior. Software may indeed be "designed to frame and constrain curiosity by replicating socio-politically dominant norms within its operational code", as Coleman points out. Democratic innovation by the help of ICTs goes via change in the communicative relationship between the governed and their governors. To code a pluralistic ethos into social and collaborative software, could be a viable way to overcome post-democracy. Carpentier indicates that our current societies are indeed permanently subject to claims for increasing participation, and that those claims do sometimes realize successfully:

In late (or post) modern societies, the frontiers of institutionalized politics have also become permeable. Discussions within the field of democratic theory indicate that it would be difficult to confine the political to the realm of institutionalized politics. Democratic theory has (sometimes) incorporated such transformations, but these theoretical expansions did not develop in a void. They grew out of a diversity of political practices that originated from actors that often were (strictly speaking) situated outside the realm of institutionalized politics. Whether they are called interest groups, old/new social movements, civil society or activists, these actors broadened the scope of the political and made participation more heterogeneous and multidirectional" (Carpentier, 2011, p. 39)

The state-of-the-art of ICTs in supporting citizen participation is in stark contrast with the bureaucratic tradition of political institutions. To public administration officials, the mere online replication of offline bureaucratic procedures already appears like an innovation. But for democratic innovation that aims at citizen empowerment, this can only be the first step on a long way to go. Political decision makers need to understand that the deployment of ICTs in democracy (i.e. eDemocracy) only makes sense if it creates additional public value.

\section{Citizen Participation in the context of Open Government}

In a broad understanding, open government trespasses mere transparency and accountability of representative institutions. It actually enriches representative democracy by the introduction of innovative forms of collaborative governance. While the pluralistic ethos of social and collaborative software is significant for the open government approach, it is - of course - by no means the only valid attempt to improve the relation between citizens and political authorities. Moore (1995) introduced the influential concept of Public Value. In a review of the literature on public value, Williams and Shearer (2011, p. 8) state that "Moore's foregrounding of the citizen-state relationship resonates with those who are disillusioned with market-based models of public sector organization and delivery but reluctant to advocate a return to prior 'statist' models of administration." They refer to Kelly et al. (2002), who attempted to "translate the public value framework into a blueprint for broader public sector improvement" and Stoker (2006), who proposed public value "as a framework for promotion of networked governance". The link between Crouch, who termed the notion of post-democracy, and public value research is not arbitrary. Crouch himself engages in establishing "[...] a theoretically rooted approach to understanding public value, providing a vantage-point for appraising Mark Moore's concept from the perspectives of history, political philosophy and sociology" (2011, p. 52). Future research on open government seems well recommended to draw on the lessons learnt from public value research concerning the relation between citizens and the public sector.

With collaborative technologies and social software being in development, the debate about citizen participation moves from a consideration of the role of technologies to one about the role of networks; 
and "it connects new forms of democratic communication to new patterns and manifestations of political power" (Coleman, 2007, p. 373). Noveck (2010, p. 63) inquires about the distinctive participative value of deliberation compared to collaboration. In the past, considerations about technology and democracy mostly focused on demographically representative conversation. Talk prevailed over action. Information was considered prior to decision-making. Whereas deliberation serves self-expression, collaboration serves participation. Additionally to ICTs, participation in agendasetting and decision-making requires collaborative networks of citizens and public administrations that develop a culture of participation.

"Collaboration occurs throughout the decision-making process. It creates a multiplicity of opportunities and outlets for engagement to strengthen a culture of participation and the quality of decision making in government itself." (Noveck, 2010, p. 64)

Many citizens - with civic hackers at the forefront - don't accept the passive stance representative democracy holds for them. From a historic perspective though, this is clearly not a new phenomenon. In the 1980s Stallman for instance advanced the philosophy of free software, which was later on turned into the mass-collaboration project GNU. In his GNU manifesto he coined the four freedoms necessary for free software development. About the political aspirations attached to the GNU project, Wikipedia.org says: "Although most of the GNU Project's output is technical in nature, it was launched as a social, ethical, and political initiative" (Wikipedia, 2011). Computer literate citizens continue to take an active approach in setting up networks demanding political participation; and continue to develop even better collaborative technologies and open software. At the heart of their initiatives is the open ethos present for instance in open access, open data, open information, open innovation, open commons, open collaboration; and open government. In the open approach socio-technical aspects meet political demands for co-creation by citizens and authorities in the online and offline world that set the frame for the discussion of open government.

The citizen's right to access public information is indispensable to be granted by law; and various provisions for transparency have been taken in the western world. In a broader sense McKenna (2011) argues for a human right to participate in the Information Society. Such a human right "[...] must be about access to decision making and access to education, to be able to use the infrastructure and possess the capacity to interact on a knowledgeable basis" (McKenna, 2011, p. 213). But granting rights on paper is not enough, if citizens are hindered to exercise their rights in practice. Even more in the US than in other western countries with more egalitarian systems, Malamud's assessment (2010, p. 45) is to be taken serious: "For too long, access to public information has been a matter of access to inside information, a matter of access to money and power". Still, in whatever country, open access to governmental data, workings and proceedings is fundamental for the improvement of democracy and justice. Beyond being a matter of transparency and public scrutiny, open access considerably favors both citizens and governments in so far that it serves as "an opportunity for citizens to help make government more efficient" (Malamud, 2010, p.46).

The various practices in different countries regarding the execution of citizen's rights to access public information in practice and the prevailing transparency and openness in a certain country is also subject to different political cultures and, in this context, to different information cultures. The general attitude towards access to information, towards transparency of structures and processes, and towards empowerment and freedom of expression pertaining to a specific society or state is deeply rooted in traditions and practices of social and cultural conditions. Information and Communication Cultures address the basic significance of having access to information and knowledge and the practices of transparency and openness in a specific society. The most important consideration involves the relationship between those who have access to information, which has a profound effect on the distribution of power of control over flows of information within society. It is assumed, that within societies with a strong hierarchical structure the flow and dissemination of public information is restricted to just a few people, while in more liberal societies there is a far broader basis for direct access to public information (Maier-Rabler, 2002).

Information-friendly societies foster the development of knowledge throughout all groups of society by providing equal and universal access to all available public information. In information-friendly societies, people have access to public information, freedom of speech is guaranteed to individuals and institutions, and the concept of universal access is understood as the equitable and affordable access to information infrastructure and to information and knowledge essential to collective and individual human development for all citizens (Maier-Rabler, 2002). 
If we turn to information-restrictive societies, however, we see they are characterized by a strong hierarchical order throughout society, leading to fewer chances for social, economic, and cultural movement. In such environments, people obtain access to relevant public information when needed. Whereby the authorities or other higher-ranking institutions or persons within the respective hierarchical system predominantly define the information. In information-restrictive cultures, the flow of information between authorities and citizens follow the push-principle whereby authorities decide which information is being passed on (Maier-Rabler, 2002).

The interrelationship between citizens and governments becomes particularly obvious in the domain of open data. All data that government has collected over time, comes from the people. It certainly belongs to the people too. Governments and administration officials are reluctant to accept that. Nevertheless, there is an ongoing debate about what data qualifies to be protected from the public. In the past, the main assumption has been that digital data generally needs to be kept in secrecy. With the open data movement however, certain change has already been established. In the context of change in the relation between citizens and government that accompanies open government, a more radical change of perspective regarding open data is still to come. DiMaio (2009) identifies two main arguments in the ongoing debate. One is, that "government provides data to citizens to provide openness and transparency". The second one is, that "citizens engage with government to improve policy-making and service delivery". Both arguments still represent an asymmetry: They pretend that data would flow mono-directionally from government to citizens and engagement vice versa from citizens to government. But actually, data flows from citizens to government and can be recombined with other existing data-sets by governments, citizens, business organizations or anybody else. Open data can improve the way governmental and non-governmental organizations deliver services, or initiate change in their policies. In 2009, DiMaio predicted that "by 2012 up to one in five government processes will be based on crowdsourced (i.e. external) data". In a future that knows a radically changed perspective on open data, not only matters of transparency and participation will stay in the foreground, but also matters of business investment in open data. Questions such as how to effectively distinguish private data government owns from its people, and how to protect it from the public; as well as how government is going to blend open data with social data created by external stakeholders, will have to be discussed (DiMaio, 2011).

Answers to these questions will be discussed and partly forged by the groups of actors who drive the open data movement. The open data study (Hogge, 2010, p. 4) found three groups principally influencing open data initiatives in the UK and the US:

- "Civil society, and in particular a small and motivated group of 'civic hackers';

- An engaged and well-resourced 'middle layer' of skilled government bureaucrats; and

- A top-level mandate, motivated by either an outside force (in the case of the UK) or a refreshed political administration hungry for change (in the US)."

The civic hackers they mention do not only influence policy debate by traditional advocacy, but also by developing demonstrator projects (p. 6). Two ways how civic hackers can be motivated by governments (or other social actors such as enterprises or universities) to develop open data applications are open data barcamps or open data competitions. In the US, open government data is provided on a portal since 2009. Besides the idea to allow citizen feedback and the development of new ideas, it was created in order to enable "transparency, participation and collaboration between state and citizen" (Hogge, 2010, p. 8). The changing relation between citizens and political authority becomes most visible in the collaboration open data platforms allow. This includes, for example, civic hackers that engage in making government-created open datasets accessible in various formats (Hogge, 2010, p. 8) and thereby provide others with the foundations they need to repurpose those datasets in other contexts. In the Austrian context, the Government Data Society runs the website www.open3.at which sets leading examples of open data use.

The role of citizens in an open government environment - enriched by open government data - can be one of democratic innovators. In an ongoing open innovation process, citizens can draw on open data, and propose both policy-areas to tackle and technical approaches to take. For open innovation to function well, open data indeed needs to stay open. O'Reilly $(2010$, p. 31) raises the concern that companies might want to make use of data created at public expense, and try to take control of it for their own profit. In order to keep open data useful for everybody, provisions have to be taken that this data cannot be copyrighted by anybody. Another key issue for an open innovation friendly 
environment are the conditions public employees are subject to. Hogge (2010) mentioned them as the second important group of people shaping open data initiatives. Change in bureaucratic culture is necessary for innovative public employees not to be punished for their engagement. To "fail forward fast" (O'Reilly, 2010, p. 35) is a way of learning.

Two elements are characteristic for open source as an open innovation approach: "shared rights to use the technology, and collaborative development of that technology" (West; Scott, 2008, p. 91). An example of open innovation, that empowers citizens and draws on open data and open source software development is the Swedish Budgetsimulator (http://www.dosf.se/medborgarbudget/). It is a "financial simulator that makes it possible to invite citizens to give their views on spending priorities for a variety of areas", as the Swedish Association of Local Authorities and Regions explains in their own words. The areas of use it allows encompass municipal operations, capital, investment and taxation. Its configuration is flexible enough to allow municipalities to opt for the use of more or less parts of the budget. Another example of valuable innovation based on open data is ubahnaufzug.at (www.ubahnaufzug.at). It consists of an application that combines open data about public transport in Vienna with user experiences of broken elevators. The result is a functionality that allows people with reduced mobility to plan their travels ahead in order to avoid sudden obstacles. As the intended and unintended outcomes of such socio-technological innovations are not always clear to the participants, and maybe not even to its proponents, they might best be understood as ongoing experiments. Its results are the product of an ICT-enhanced peer-production process that puts political authorities and citizens on a more equal basis. The lessons learnt from such innovative democratic projects help to improve the involved patterns of collaboration and the software that supports them iteratively. The challenge is to provide the technological means to enable collaboration at scale. This requires both designing practices that make participation manageable and useful, and designing software that supports such practices. "Hence, designing new democratic institutions also depends on designing the appropriate collaborative practices and embedding that design in software" (Noveck, 2010, p. 64).

\section{The citizens' right to Open Government Platforms}

Governmental data represents historically grown collective knowledge. According to Sen's theory of justice, every citizen has got the right to realize his or her capabilities (Sen, 1985). The use of governmental data must not be restricted to governmental officials. Actually, the denomination of that data should express the public right to access and to make use of it. Open data is a useful expression to convey the idea of collective knowledge. In the hands of their owners - (i.e. the citizens), the value of data grows as it creates more knowledge. Reason for that lies in the network character of knowledge. "Knowledge has to be related to other knowledge if it is to count as knowledge" (Gottschalk-Mazour, 2007, p. 220). Both internally and externally, knowledge is networked. An isolated chunk of data is worth as little as an isolated chunk of knowledge. Only by (re)combination, data can turn into valuable knowledge.

In a pluralistic society, even the positive or negative connotation of certain data can change. O'Reilly (2009) mentions applications that "take government crime statistics and turn them into public safety applications for the Web or iPhone". Aggregated open public data (nota bene not personal data) can be beneficial for various kinds of communities. Many networks that draw on open data (e.g. http://www.everyblock.com/) support citizens in their daily life at municipal level. This corresponds with Crouch's idea of solving problems of post-democracy best on the local level $(2008$, p. 145). Unlike centrally planned actions, "networks are characterized by the ability to foster spontaneous order, an order (rational and benevolent) that emerges from bottom-up without any centralized planning, external governance, or oversight" (Fisher, 2010, p. 212, original emphasis). The prerequisite for the functioning of networks is a common infrastructure. The role of government is to provide that infrastructure.

"To flourish, a networked information economy rich in social production practices requires a core common infrastructure, a set of resources necessary for information production and exchange that are open for all to use. This requires physical, logical, and content resources from which to make new statements, encode them for communication, and then render and receive them." (Benkler, 2006, p. 470) 
The core common infrastructure Benkler envisages is similar to O'Reilly's concept of government as a platform $(2009,2009 B)$. Open platforms run by government relate very differently to citizens than any hierarchical form of bureaucracy. They enable citizens to experience authentic empowerment. In O'Reilly's terms they enable "anyone with a good idea to build innovative services that connect government to citizens, give citizens visibility [...] and even allow citizens to participate directly in policy making" (2009). The citizen-driven recombination of open data both allows to take on new perspectives on given problems as well as to raise awareness on new issues that have not yet been considered a priority within the hierarchical structures of public administration. But open government platforms don't just provide open data. Among the government information, that should be open to the public, Malamud (2010, p. 44) counts for example patents, agricultural and medical research, corporate filings, information on the weather, and maps. He considers them to be the raw material of innovation from which tremendous economic value can be drawn to society. "Government information is a form of infrastructure, no less important to our modern life than roads, electrical grid, or water systems" (Malamud, 2010, p. 44). Paraphrasing Sen, every citizen has got the right to access this basic infrastructure in order to live up to his or her capabilities.

DiMaio (2011B) draws attention to yet another potential benefit of open government platforms that upright citizens could feel entitled to. Instead of limiting the idea of open government to networked citizens using open data for innovative projects, DiMaio proposes incentives that lead to collaboration between government and citizens on tax matters. He suggests that "the application development community could be engaged, by launching contests and hackatons for them to come up with smart apps that use - among other things - open data to help catch non compliant taxpayers". Therein he sees an appropriate way of fighting tax evasion, enabled by government-citizen collaboration on open platforms. The definite form and unintended implications of such collaborative experiments enabled by open government platforms are still unknown. It is nevertheless obvious that some citizens will go ahead to enforce their own radical idea of transparency and citizen empowerment, circumventing prior public debate and consent (e.g. www. wikileaks.org), if governments fail to offer adequate platforms. In that case, governments miss out on an opportunity to co-create collaborative practices together with citizens.

Although it cannot be sufficiently elaborated within this article, we would like to mention at this point that access to data and information is not enough. Open government must embrace activities to train and educate the citizens in order to make them capable to benefit from transparency and openness. Jesse Lichtenstein addressed this issue recently in an article in Wired magazine, quoting Michael Gurstein, a community informatics expert in Vancouver, British Columbia, who has dubbed this problem the data divide - in analogy to the digital divide.

The concern that open data may simply empower the empowered is not an argument against open data; it's an argument against looking at open data as an end in itself. Massive data dumps and even friendly online government portals are insufficient. Ordinary people need to know what information is available, and they need the training to be conversant in it. And if people are to have anything more than theoretical access to the information, it needs to be easy and cheap to use. That means investing in the kinds of organizations doing outreach, advocacy, and education in the communities least familiar with the benefits of data transparency. If we want truly open government, we still have to do the hard work of addressing basic and stubborn inequalities. However freely it flows, the data alone isn't enough. (Lichtenstein, 2011)

\section{Research perspectives and conclusions on Open Government}

It was argued above, that open government empowers the role of citizens - the governed - in relation to government. Generally speaking, open government offers added value to citizens in the form of innovative participatory practices and opportunities for networking and collaboration. It would indeed "be a tragedy were 'digital democracy' merely to create virtual parallels of obsolescent political processes and structures" (Coleman, 2007, p. 377). The concrete value of open government for the public is yet to determine. Indeed, only if the combination of ICTs and democracy generates additional value for society, e-participation makes sense. One research tradition that deals with questions of value "beyond narrow monetary outcomes to include that which benefits and is valued by the citizenry more generally" (Williams; Shearer, 2011, p. 1) is public value research. 
The public value framework was originally set up by Moore (1995) within the context of strategic management in government. Kelly (2002) and others have tried to adopt the public value concept for broader public sector improvement. They assume that only the public itself can determine what is of public value. According to their approach, a public service is of value, if citizens are willing to reciprocate individually or collectively (Gundlach, 2011, p. 14). From that point of view, open government platforms qualify for public value research in as much as they are collectively financed by public money (i.e. taxpayer's money on all kinds of political and/or administrative levels). A second argument for using the public value approach for research on open government platforms is the mentioned assumption of added value: what is the concrete public value of open government concerning the political power and role of citizens? In their thorough literature review on scientific research about public value, Williams and Shearer acknowledge an "apparent silence of public value on questions of power and heterogeneity" $(2011$, p. 1). They conclude with a proposition for future research: "The task for future researchers must therefore be to define the central concepts and arguments that make up public value and subject these to empirical investigation and testing" (p. 15)

Unlike the public value approach, research into ICTs has developed strands that particularly focus on power relations. Green and Haddon (2009, p. 110) name four of them: First are studies about inequalities in access to and experiences with ICTs that came to be known as digital divide. Second come studies that focused on particular variables like age, culture, and gender. The third research strand examines the role of ICTs with respect to formal politics. This includes studies on the potential of innovative ICTs for increased participation in established political processes, and its potential in creating alternative political spheres. A fourth strand finally deals with matters of regulation and control of ICTs. Within those four categories, research on the public value of open government fits best with the third strand that deals with the potential of innovative ICTs and the collaborative networks they support.

In this sense, a number of case studies will have to be conducted on various examples of open government initiatives, actions, applications and platforms on national and local level. In the framework of public value research, empirical studies on the empowered role of citizens in open government can help to

"focus on the responsibility of the public themselves to identify what is considered 'valuable' so that citizens are not just recipients and beneficiaries of public interventions but also designers of public enterprise and constitutive of the institutions of public service delivery" (Williams; Shearer, 2011, p. 13).

We argue that meaningful e-participation demands political authorities to engage in collaboration, codecision, co-development and shared responsibilities with public administration and citizens. More than public administration officers, elected politicians ought to take the lead in such an innovation process. Most likely by allowing and empowering citizens to accept more responsibilities in public live, and by authorizing public officials to help create public value in citizen's priority areas. The assertion of leadership by politicians is not in contradiction to the public value approach, as public value "cannot be achieved without government and political leadership" (Benington, 2011: p. 50). Likewise, those issues concerning the relation between citizens, public administration, and political authority deserve more attention in research on open government. Over the last 15 years the public value approach has evolved way beyond public service issues. Benington and Moore claim that the new pattern of polycentric networked governance requires capabilities to think and act along several political dimensions. What is required nowadays is

"a radically different approach to policy development and public management, with a need to link policy to implementation, and strategy to operations, in and end-to-end process which can deliver greater public value - through practical action on the ground at the front line with communities." (Benington; Moore, 2011: p. 15).

We argue that local open data initiatives and applications, community budged simulators, participatory online budgetings on municipal level and various other open government examples are potentially important nodes in polycentric networked governance.

Future dynamics of open government can be assessed following an adapted version of the public value approach. Conditions and criteria of public value research need to be developed concerning open government as a whole, as well as particular applications. We understand open government as a 
potential for democratic innovation from a citizen perspective, in close collaboration with government and public administration. Therefore open government platforms are an essential technological milestone for citizen empowerment.

\section{References}

Balnaves, M. \& Willson, M. (2011) A new theory of information \& the internet: public sphere meets protocol, New York: Peter Lang.

Benington, J. \& Moore, M. H. (2011) Public Value: Theory \& Practice, Basingstoke: Palgrave Macmillan.

Benington, J. (2011) From Private Choice to Public Value? In: Benington, J. \& Moore, M. H. (2011) Public Value: Theory \& Practice, Basingstoke: Palgrave Macmillan.

Benkler, Y. (2006) The wealth of networks: how social production transforms markets and freedom, New Haven: Yale University Press.

Carpentier, N. (2011) Media and Participation: A site of ideological-democratic struggle, Bristol: Intellect.

Coleman, S. (2007) e-Democracy: The history and future of an idea, In: Mansell, R. \& Avgerou, C. \& Quah, D. \& Silverstone, R. (2007). The Oxford Handbook of Information and Communication Technologies, Oxford: Oxford University Press.

Crouch, C. (2008) Postdemokratie, Frankfurt am Main: Suhrkamp.

Crouch, C. (2011) Privates, Publics and Values, In: Benington, J. \& Moore, M. H. (2011) Public Value: Theory \& Practice, Basingstoke: Palgrave Macmillan.

DiMaio, A. (2011) How To Get Open Government Out Of Life Support, retrieved August 25 from http://blogs.gartner.com/andrea dimaio/2011/08/05/how-to-get-open-government-out-of-life-support/

DiMaio, A (2009) Fighting the asymmetry of Government 2.0, retrieved August 25 from http://blogs.gartner.com/andrea dimaio/2009/11/11/fighting-the-asymmetry-of-government-2-0/

Di Maio, A (2009B) It is time to use Gov 2.0 to solve intractable problems, such as fighting tax evasion in Italy, retrieved August 25 from http://blogs.gartner.com/andrea dimaio/2011/06/22/it-is-time-to-use-gov-2-0-to-solve-intractable-problems/

Green, N. \& Haddon, L. (2009) Mobile communication: An introduction to new media, Oxford: Berg

Gottschalk-Mazouz, N. (2007) Internet and the flow of knowledge: Which ethical and political challenges will we face?, In: Hrachovec, H. \& Pichler, A. (2007) Philosophy of the information society: Proceedings of the 30. International Ludwig Wittgenstein Symposium, Volume 2, Frankfurt: Ontos.

Fisher, E. (2010) Media and new capitalism in the digital age: the spirit of networks, Basingstoke: Palgrave Macmillan

Gundlach, H. (2011) Public Value in der Digital- und Internetökonomie, Köln: Herbert von Halem Verlag.

Hogge, B. (2010) Open data study: new technologies, London: Transparency \& Accountability Initiative, retrieved August 25 from http://www.transparency-initiative.org/wp-content/uploads/2011/05/open data study final.pdf

Kelly, K. \& Mulgan, G. \& Muers, S. (2002) Creating public value: an analytical framework for public service reform, London: Cabinet Office.

Lathrop, D. \& Ruma, L. (2010) Open government: collaboration, transparency, and participation in practice, Sebastopol: O'Reilly Media.

Lichtenstein, J. (2011) Why Open Data Alone Is Not Enough. In: Wired Magazine, July 2011, retrieved September 12 from http://www.wired.com/magazine/2011/06/st_essay_datafireworks/

Maier-Rabler, U. (2002) Cultural Aspects and Digital Divide in Europe. In: Medien Journal 3/2002, p. 14-32.

Malamud, C. (2010) By the people, In: Lathrop, D. \& Ruma, L. (2010) Open government: collaboration, transparency, and participation in practice, Sebastopol: O'Reilly Media.

McKenna, A. (2011) A human right to participate in the information society. New York: Hampton Press.

Moore, M. (1995) Creating public value: strategic management in government, Cambridge: Harvard University Press.

Noveck, B. (2010) The single point of failure, In: Lathrop, D. \& Ruma, L. (2010) Open government: collaboration, transparency, and participation in practice, Sebastopol: O'Reilly Media.

OECD (2011) The call for innovative and open government: an overview of country initiatives, retrieved August 25 from http://dx.doi.org/10.1787/9789264107052-en

O'Reilly, T. (2010) Government as a platform, In: Lathrop, D. \& Ruma, L. (2010) Open government: collaboration, transparency, and participation in practice, Sebastopol: O'Reilly Media.

O'Reilly, T. (2009) Gov 2.0: The promise of innovation, retrieved August 24 from http://www.forbes.com/2009/08/10/government-internet-software-technology-breakthroughs-oreilly.html

O'Reilly, T. (2009B) Gov 2.0: It's all about the platform, retrieved August 24 from http://techcrunch.com/2009/09/04/gov-20-itsall-about-the-platform/

Sen, A. (1985) Commodities and Capabilities, Amsterdam: Elsevier Science Ltd. 
Swedish Association of Local Authorities (2011) Dialog with the citizens, retrieved August 25 from http://www.skl.se/vi arbetar med/demos/demokratiutveckling/medborgardialog/medborgardialog med it stod/dialogue w ith the citizens

Warren, M. E. (2011) Citizen Participation and Democratic Deficits : Considerations from the Perspective of Democratic Theory, retrieved November 22, from: http://www.politics.ubc.ca/fileadmin/template/main/images/departments/poli sci/Faculty/warren/Citizen Partici pation and Democratic Deficits Draft 5.pdf

West, J. \& Gallagher, S. (2008) Patterns of open innovation in open source software. In: Chesbrough, H. \& Vanhaverbeke, W. \& West, J. (2008) open innovation: researching a new paradigm, Oxford: Oxford University Press.

Wikipedia: GNU Project. Retrieved November 25, from: http://en.wikipedia.org/wiki/GNU Project

Williams, I. \& Shearer, H. (2011) Appraising public value: past, present and futures, In: Public Administration (2011) Oxford: Blackwell Publishing Ltd. Retrieved August 25 from http://onlinelibrary.wiley.com/doi/10.1111/j.1467$\underline{\text { 9299.2011.01942.x/pdf }}$

\section{About the Authors}

Ursula Maier-Rabler

Ursula Maier-Rabler is head of the the ePolicy \& eSociety Unit at the interdisciplinary "Center for advanced research and studies in information and communication technologies and society" (ICT\&S Center) at the University of Salzburg, Austria. Besides her basic research interest in the Internet and digital networks, and their interrelationship with society, issues like e-democracy and e-participation, eLearning and cultures of information and communication are in the center of her focus. Current e-policy research, in particular comparative studies on ICT-policies of European Member States, attempt to identify different policy practices and introduce a culturally sensitive e-policy model

Stefan Huber

Stefan Huber is a doctoral researcher at the ePolicy \& eSociety Unit of the ICT\&S Center at Salzburg University. He obtained an MA in political science at Salzburg University and the CEP of the Institut d'Etudes Politiques (IEP) de Rennes, France. His research comprises e-democracy, e-participation, open government and open data, participatory society, new media literacy and political education, public value and participatory online budgeting. 